\title{
STUDY OF INVERSION OF UTERUS IN TERTIARY CARE HOSPITAL
}

\author{
Shrinivas Gadappa ${ }^{1}$, Kannan Yelikar², Nutan Wanjare ${ }^{3}$ \\ ${ }^{1}$ Associate Professor, Department of Obstetrics and Gynaecology, Government Medical College, Aurangabad. \\ 2 Professor and HOD, Department of Obstetrics and Gynaecology, Government Medical College, Aurangabad. \\ ${ }^{3}$ Resident, Department of Obstetrics and Gynaecology, Government Medical College, Aurangabad.
}

\section{ABSTRACT}

Introflexion of Parietis Uteri or Uterine inversion is the turning inside out of the fundus into the uterine cavity with incidence ranging from $1: 2500 .{ }^{[1,2]}$ to $1: 20000 .[2,3]$ Various aetiological factors have been linked to uterine inversion, though no obvious causes are found. Mismanagement of third stage of labour has been found to be the leading cause.

\section{OBJECTIVE}

To study the incidence, clinical presentation, management protocols used including surgical techniques in cases of uterine inversion and its outcome.

\section{METHOD}

This is an observational study carried out at GMCH Aurangabad during the years 2000 to 2014 .

\section{CONCLUSION}

Uterine inversion is a life threatening and unpredictable obstetric emergency, which if ignored can lead to severe haemorrhage and shock. When managed promptly and aggressively, uterine inversion can result in minimal maternal morbidity and mortality.

\section{KEYWORDS}

Uterine inversion, Obstetric emergency, Shock, Postpartum haemorrhage, Introflexion, postpartum collapse

HOW TO CITE THIS ARTICLE: Shrinivas Gadappa, Kannan Yelikar, Nutan Wanjare. "Study of Inversion of Uterus in Tertiary Care Hospital." Journal of Evolution of Medical and Dental Sciences 2015; Vol. 4, Issue 98, December 07; Page: 16305-16308, DOI: $10.14260 /$ jemds/2015/2406

\section{INTRODUCTION}

Hippocrates (c. $460-377$ B.C.). ${ }^{1}$ mentioned uterine inversion, as did Soranus of Ephesus in 110 A.D., ${ }^{2,3,4}$ but it was not until the 16th century during the time of Ambroise-Paré, that it was understood.5,6 Uterine inversion can be either puerperal (Obstetric) or non-puerperal (Gynaecological). Puerperal uterine inversion is a rare, but potentially life threatening obstetric emergency. Patients may be present with sudden postpartum collapse. It is imperative that the condition be recognized quickly and promptly managed in order to minimize the potential for maternal morbidity and mortality. The incidence of uterine inversion varies and ranges from $1: 2500 .{ }^{[1,2]}$ to $1: 20000 .[2,3]$ Being a tertiary referral centre, there is a high incidence of uterine inversion observed with different clinical presentations.

Various aetiological factors have been linked to uterine inversion, though no obvious causes are found. Attributable factors include short umbilical cord, fundal implantation of placenta, excessive traction on umbilical cord, fundal pressure, adherent of placenta, uterine atony, and rarely connective tissue disorders (Marfan syndrome, Ehlers-Danlos syndrome).

Financial or Other, Competing Interest: None.

Submission 25-10-2015, Peer Review 26-10-2015,

Acceptance 04-11-2015, Published 04-12-2015.

Corresponding Author:

Dr. Shrinivas Gadappa,

Associate Professor

Department of Obstetrics and Gynaecology,

Government Medical College,

Aurangabad.

E-mail: gadappashrinivas@gmail.com

DOI:10.14260/jemds/2015/2406
It is well established that mismanagement of the third stage of labour is the commonest cause of acute uterine inversion.

Uterine inversion can be of various degrees, from partial to complete. According to the delay between the delivery and the diagnosis, uterine inversion can be classified as:

1. Acute - Immediately or within 24 hours after delivery.

2. Subacute- Occurring after 24 hours to upto 4 weeks after delivery.

3. Chronic- Arising after 4 weeks of delivery. ${ }^{1}$

Once the diagnosis is established, immediate management of uterine inversion includes resuscitation and stabilization of patient with simultaneous attempts to reposit the uterus. Uterus should be replaced manually through the vagina past the cervical ring with pressure directed upwards towards the umbilicus.

This is commonly referred to as Johnson's method. If this fail, hydrostatic replacement is the next step. This technique was initially described by O'Sullivan in 1945 . Use of an intrauterine balloon catheter (Modified hydrostatic method) has also been reported. Hydrostatic intrauterine balloon tamponade, "This is a 'balloon' usually made of synthetic rubber balloon catheters such as Foley catheters, Rusch catheters, SOS Bakri catheters, Sengstaken-Blakemore and even using sterile rubber glove condom.

Surgical procedures are indicated when manual reduction fails. Huntington procedure involves a laparotomy to locate the cup of the uterus. Allis forceps are applied to the round ligaments and upward traction given until the inversion is corrected. Hualtain's technique involves division of cervical ring posteriorly prior to applying traction as in Huntington's procedure.1,3 


\section{MATERIAL AND METHODS}

This study was carried out in Government Medical College, Aurangabad, during years 2000 to 2014 .

All cases of uterine inversions have been included in study. Total 25 cases were of uterine inversion, 18 were puerperal and 7 were non-puerperal.

Detail analysis was done regarding the presentation of disease, management protocol applied, surgical technique used if any and maternal outcome.

\section{OBSERVATION Incidence}

- Total No. of deliveries in 2000 to $2014=1,78,850$.

- Prev. incidence varies from 1:15,000 to 1:22,000.

- We have studied 18 puerperal cases of inversion of uterus.

\begin{tabular}{|c|c|c|c|c|c|c|c|c|c|}
\hline & \multicolumn{4}{|c|}{ Parity } & \multicolumn{2}{c|}{ Place of Delivery } & \multicolumn{3}{c|}{ Type of Inversion } \\
\cline { 2 - 9 } & I & II & III & IV & Home & Hospital & Acute & Subacute & Chronic \\
\hline Puerperal 18 & 12 & 2 & 0 & 4 & 14 & 4 & 16 & 2 & 0 \\
\hline
\end{tabular}

Table 1: Table showing Puerperal Inversion Cases with Parity and Type of Inversion

\begin{tabular}{|c|c|c|}
\hline Symptoms & Puerperal (\%) & Non-Puerperal (\%) \\
\hline Shock & $15(83 \%)$ & 0 \\
\hline Altered discharge & $3(16 \%)$ & $4(57 \%)$ \\
\hline $\begin{array}{c}\text { Constant lower abdominal pain } \\
\text { and bearing down sensation }\end{array}$ & $10(55.5 \%)$ & $4(57 \%)$ \\
\hline Retention of urine & $4(22.2 \%)$ & $1(5 \%)$ \\
\hline $\begin{array}{c}\text { Reddish purpule foul smelling } \\
\text { mass protruding out through vulva }\end{array}$ & $10(55.5 \%)$ & $3(16 \%)$ \\
\hline Diagnosed on laparotomy & 0 & $1(5 \%)$ \\
\hline \multicolumn{2}{|r}{ Table 2: Table showing Clinical Features } \\
\hline
\end{tabular}

\begin{tabular}{|c|c|c|c|c|c|c|c|c|c|c|c|c|c|c|c|c|}
\hline \multirow[b]{2}{*}{$\begin{array}{l}\mathscr{d} \\
\text { J } \\
\tilde{J}\end{array}$} & \multicolumn{4}{|c|}{ Vitals } & \multicolumn{5}{|c|}{ Blood Transfusions } & \multicolumn{6}{|c|}{ Complications } & \multirow[b]{2}{*}{ 䒕 } \\
\hline & 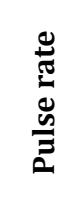 & 官 & $\begin{array}{l}\stackrel{\circ}{ } \\
\text { ஸे } \\
\text { ஸे }\end{array}$ & 主 & $\begin{array}{l}\frac{5}{0} \\
\frac{0}{0} \\
\frac{0}{0} \\
\frac{2}{3}\end{array}$ & $\vec{Z}$ & $\begin{array}{l}\frac{n}{0} \\
\frac{0}{0} \\
\frac{\pi}{a}\end{array}$ & $\frac{0}{\frac{T}{x}}$ & 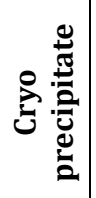 & $\begin{array}{l}\frac{\pi}{\breve{~}} \\
\frac{\AA}{\omega}\end{array}$ & $\frac{\text { L }}{\frac{\alpha}{\alpha}}$ & $\overrightarrow{0}$ & $\begin{array}{l}\frac{n}{\omega} \\
\frac{0}{2} \\
\dot{s}\end{array}$ & 華 & $\begin{array}{l}\dot{d} \\
\bar{\Xi} \\
\vec{z} \\
\vec{z}\end{array}$ & \\
\hline 1 & 120 & $90 / 60$ & 90 & 9 & 2 & 2 & 1 & 4 & 2 & + & & & & & & A \\
\hline 2 & 112 & $86 / 50$ & 94 & 7 & 3 & 3 & 2 & 6 & 2 & + & + & & & & & $\mathrm{A}$ \\
\hline 3 & 132 & $100 / 60$ & 92 & 7 & 2 & 2 & 0 & 4 & 2 & + & & + & & & & B \\
\hline 4 & 120 & $86 / 56$ & 96 & 8 & 2 & 2 & 0 & 4 & 2 & + & + & & + & & & A \\
\hline 5 & 150 & $84 / 40$ & 84 & 8 & 1 & 3 & 0 & 2 & 0 & & & & & & & A \\
\hline 6 & 124 & $88 / 40$ & 88 & 6 & 4 & 0 & 1 & 4 & 0 & + & & + & & & & $\mathrm{B}$ \\
\hline 7 & 140 & $90 / 40$ & 82 & 8 & 2 & 3 & 2 & 4 & 0 & + & & + & & & & $\mathrm{A}$ \\
\hline 8 & 110 & $100 / 60$ & 80 & 7 & 2 & 3 & 2 & 2 & 2 & + & & & & & & $\mathrm{C}$ \\
\hline 9 & 126 & $90 / 60$ & 94 & 8 & 2 & 2 & 1 & 4 & 2 & & & & & & & $\mathrm{~B}$ \\
\hline 10 & 124 & $84 / 50$ & 92 & 7 & 2 & 2 & 2 & 2 & 2 & + & & + & + & & & $\mathrm{C}$ \\
\hline 11 & 130 & $100 / 60$ & 90 & 7 & 2 & 3 & 2 & 4 & 0 & + & & & & & & $\mathrm{D}$ \\
\hline 12 & 128 & $80 / 60$ & 90 & 8 & 4 & 0 & 4 & 2 & 0 & + & & & + & + & & $\mathrm{B}$ \\
\hline 13 & 132 & $90 / 50$ & 94 & 8 & 1 & 3 & 1 & 2 & 0 & + & + & & & & & $\mathrm{B}$ \\
\hline 14 & 112 & $86 / 56$ & 92 & 9 & 1 & 3 & 2 & 2 & 2 & + & & & & & & $\mathrm{D}$ \\
\hline 15 & 126 & $90 / 40$ & 90 & 7 & 2 & 2 & 2 & 2 & 2 & + & & + & & & & $E$ \\
\hline 16 & 140 & $98 / 60 /$ & 94 & 7 & 1 & 3 & 2 & 2 & 0 & + & & & & & & $\mathrm{A}$ \\
\hline 17 & 124 & $100 / 60$ & 92 & 9 & 1 & 2 & 2 & 4 & 0 & + & & & & + & & $\mathrm{A}$ \\
\hline 18 & 100 & $80 / 60$ & 90 & 9 & 2 & 2 & 2 & 4 & 2 & + & & & & & & A \\
\hline & & & & & & & & & & & & & & & & \\
\hline
\end{tabular}

A. Immediate reposition on table; B. Repositon under anesthesia; C. Rubber glove tamponade; D. Hualtain's repair; E. Hysterectomy;

BP-Blood pressure, SPO2-oxygen saturation, PCV-packed cell volume, FFP-Fresh frozen plasama, ARF-Acute renal failure, DIC- Disseminated intravascular coagulation, ARDS- Acute respiratory distress syndrome.

\section{DISCUSSION}

In several series of cases and literature reviews, no obvious cause has been found to account for $40 \%$ of cases of acute puerperal inversion; hence in these cases the condition has been referred to as spontaneous.
There has been remarkable consistency in the reported frequency of spontaneous inversion and what is of greater importance is the occurrence of 8 cases that can be directly attributed to improper management of the third stage of labour. 
Undoubtedly, active management of the third stage of labour has decreased the frequency of postpartum hemorrhage without increasing the occurrence of retention of the placenta. Timing of the inversion may be acute (Within 24 hours of delivery), subacute (More than 24 hours postpartum) or it may be chronic (More than 4 weeks postpartum); the prevalence of each class is $83.4 \%, 2.6 \%$ and $13.9 \%$ respectively. ${ }^{[4]}$ In our set up prevalence of each class is $88.8 \%, 11.12 \%$ and $0 \%$ respectively.

Non-puerperal uterine inversion is usually precipitated by tumours sited at the fundus of the uterus, which exert traction force to cause the inversion, although some cases have been reported with no association with tumours

The presentation of the uterine inversion will vary depending on the severity of the inversion. The haemorrhage strength is directly related to the duration of inversion. The bleeding is massive in more than $70 \%$ of cases and shock is the most constant sign. $[7,8,9,10,11,12]$ It results from hypovolaemia which is secondary to bleeding and vagal reaction associated with stretching of the nervous fibres contained in uterine ligaments.[10,11,12,13,14,15] The sudden severe pain is less frequent and is present in $7 \%$ to $10 \%$ of cases.

In our study, $83 \%$ puerperal inversion presented with bleeding and shock and followed by lower abdominal severe pain in $55.5 \%$ of cases.

The key approach which is usually successful if done immediately is a non-surgical technique referred to as Johnson's method. Out of 18 cases, we have reposited 6 cases on table $(33.3 \%)$ and in 5 cases reposition of uterus under anesthesia $(27 \%)$ were done successfully.

If manual reposition fails to achieve uterine repositioning, then employing the use of hydrostatic method would be the next approach. We did 2 cases successfully with a rubber glove tamponade with $100 \%$ result in arrest of bleeding. In another study, a rubber glove tamponade arrest or stop bleeding in $77.5 \%$ to $88.8 \%$ or more cases without any further need for surgical treatment."16,17 Other reviews state that the balloon tamponade is effective in $91.5 \%$ of cases and recommend that this relatively simple technology be part of existing protocols in the management of PPH. ${ }^{16}$ Further, the balloon tamponade can test if the bleeding is uterine or from another source. If the bleeding does not stop with inflation, it is likely to be coming from a laceration or cause other than uterine atony.

If uterine inversion has persisted despite non-surgical approach, then surgery will usually be required. For three cases of inversion, we did surgical management i.e. Hualtain's repair and hysterectomy. In our study, $16 \%$ cases required surgical management.

Out of 18 cases, 3 maternal mortality occurred because patient landed up in acute renal failure, sepsis and DIC. Therefore, it is paramount that further assistance is promptly summoned, so that the patient can be effectively resuscitated and appropriately stabilized. Maternal morbidity may be significant with an uterine inversion and mortality rates approach $15 \%\left[{ }^{[13]}\right.$ We reported maternal moratlity around $16 \%$ with uterine inversion as patients are diagnosed in early phase with receiving early primary life saving treatment.

In 7 non-puerperal inversion cases of fibroid with polyp 4 cases were with third degree inversion of uterus; 3 cases were of second degree type of inversion of uterus, one of them was diagnosed during laparotomy. We did surgical management i.e., hysterectomy or polypectomy followed by hysterectomy with good outcome of patient.

\section{CONCLUSION}

From our study of 18 cases of puerperal and 7 non-puerperal uterine inversion, both physiologic and active forms of management of the third stage of labour are acceptable, although routine active management will diminish the frequency of postpartum hemorrhage.

Uterine inversion is an unusual and potentially lifethreatening complication of third stage of labour. The morbidity and mortality associated with this complication can be decreased by prompt diagnosis and early initiation of pertinent treatment. In non-puerperal inversion of uterus, the most common cause is fibroid polyp.

In puerperal inversion of uterus, most common presentation is bleeding and shock $(83 \%)$ followed by severe lower abdominal pain (55.5\%). Hence, in all patients of postpartum haemorrhage with shock, one should keep high degree of suspicion of inversion of uterus. As at this stage if patient gets the correct treatment, then morbidity and mortality can be avoided. We conclude that proper education and training regarding placental delivery, diagnosis and management of uterine inversion should be given, so that this potentially life-threatening condition can be prevented.

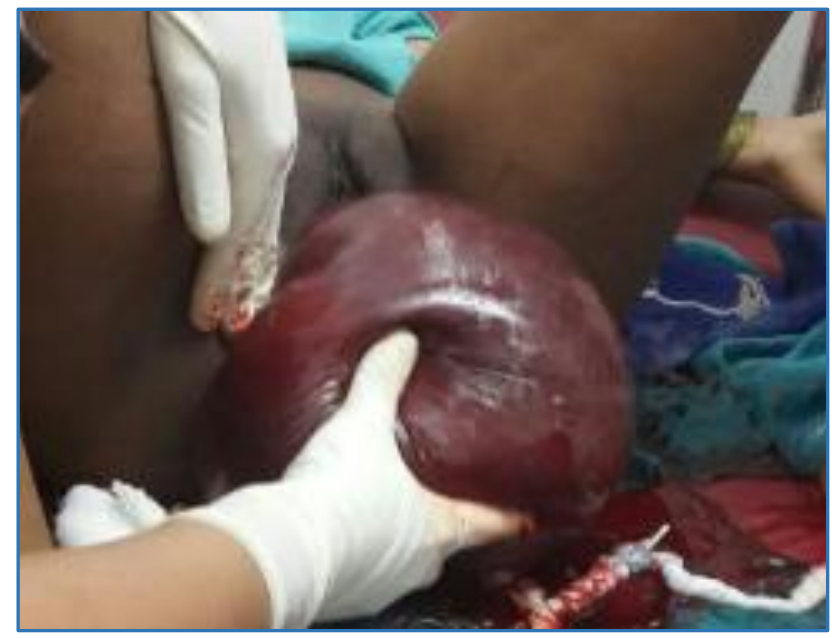

Fig. 1: Showing Inversion of Uterus with Placenta in Situ

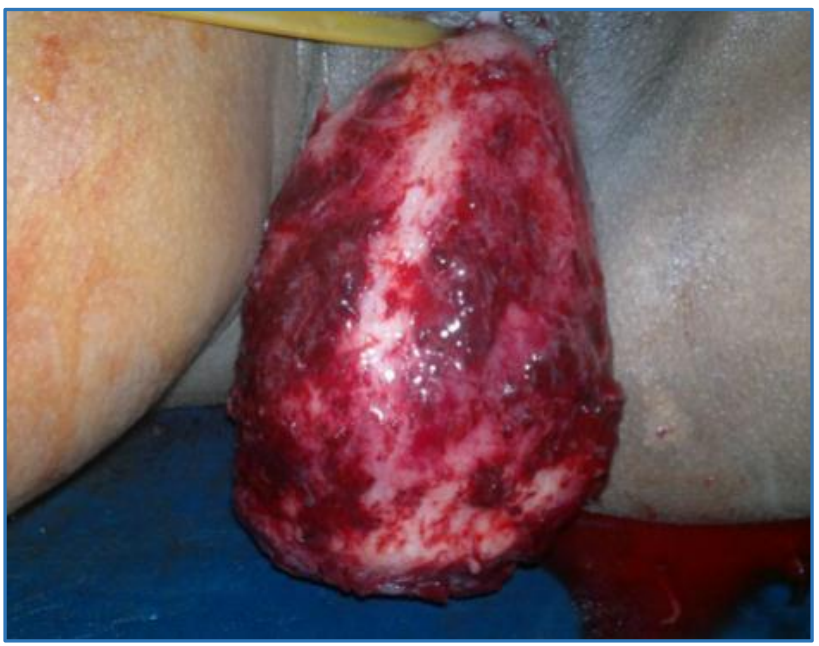

Fig. 2: Showing Third Degree Inversion of Uterus 


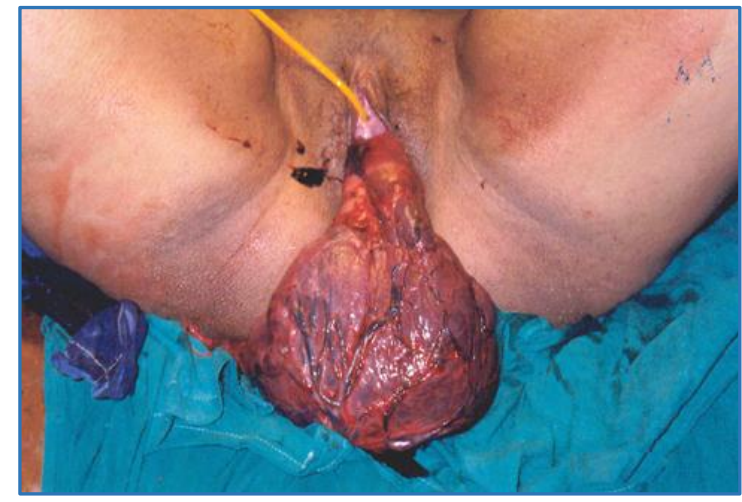

Fig. 3: Showing Third Degree Inversion of Uterus with Placenta in Situ

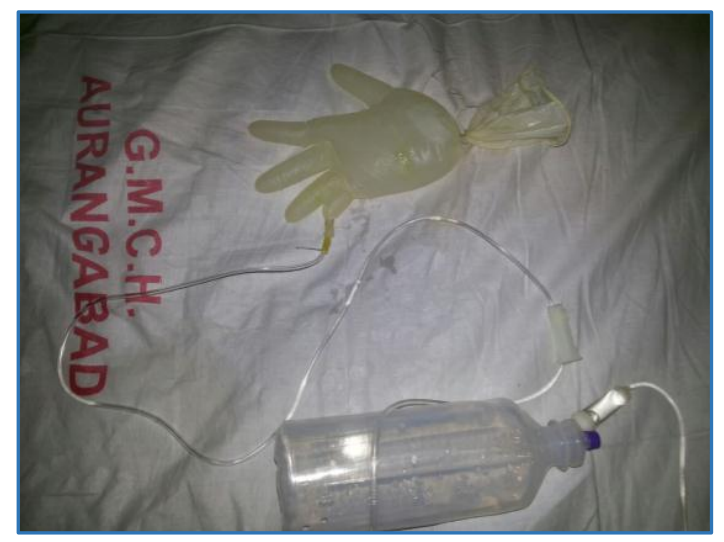

Fig. 4: Showing Balloon Glove Catheter Used in Atonic Uterus

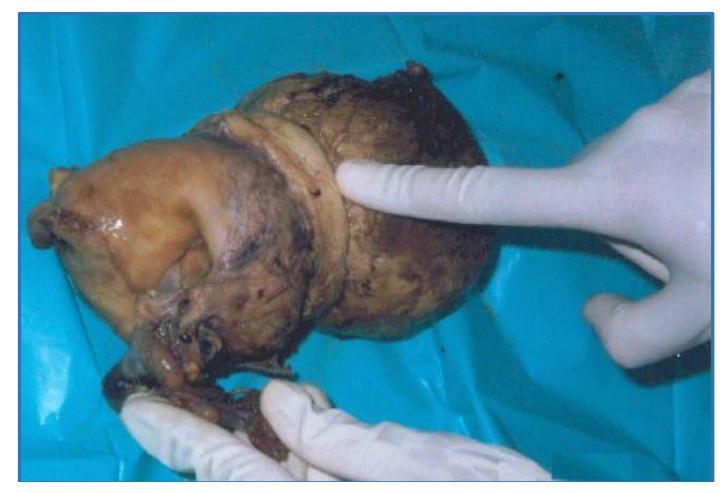

Fig. 5: Non Puerperal Inversion of Uterus

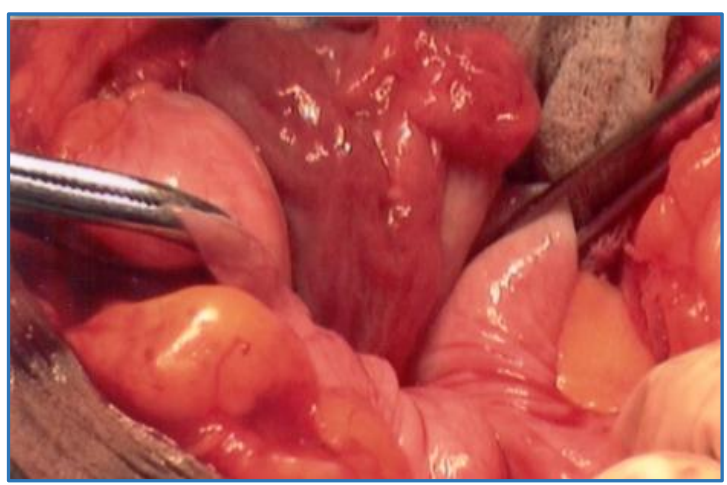

Fig. 6: Classical Flower Vase Appearance of Inversion of Uterus

\section{REFERENCES:}

1. You WB, Zahn CM. Postpartum Hemorrhage: Abnormally Adherent Placenta, Uterine Inversion, and Puerperal Hematomas. Clinical Obstetrics and Gynecology. 2006;49(1):184-97.

2. Mirza FG, Gaddipati S. Obstetric Emergencies. Seminars in Perinatology 2009;33:97-103.

3. Coates T. Midwifery and obstetric emergencies. In: Fraser DM, MA C, editors. Myles Textbook for Midwives. 15th ed. London: Churchill Livingstone; 2009. p. 625-47.

4. Dali SM, Rajbhandadari S, Shrestha S. Puerperal inversion of the uterus in Nepal: case reports and review of literature. J ObstetGynaecol Res 1997;23:319-25.

5. Krenning RA, Dorr PJ, De Groot WH, De Goey. WB. Nonpuerperal uterine inversion. Case report. Br J Obsetet Gynaecol 1982;89:247-9.

6. Gowri, Vaidyanathan. Uterine inversion and corpus malignancies: a historical review. Survey. ObstetGynaecol Survey 2000;55:703-7. Doi: 101097/00006254200011000-

7. Druzon ML, Platt LD: Acute puerperal inversion of the uterus. Am J ObstetGynaecol 1981;141:187.

8. Achanna S, Mohamed Z, Krishnan M. Puerperal uterine inversion: a report of four cases. Journal of Obstetric and Gynaecology Research 2006;32(3):341-345.

9. Harbinder S, Greenspoon JS, Platt LD, Paul RH. Journal of reproductive medicine 1989;34(2):173-177.

10. Lago J. Presentation of acute uterine inversion in the emergency departement. Am J Emerg Med 1991;9:239-42.

11. Chambrier C, Zayneh E, Pouyau A, Pacome JP, Bouletreau P. Uterine inversion: an anesthetic emergency. Ann FrAnesthReanim 1991;10:81-3.

12. Miras T, Collet F, Seffert P. Acute puerperal uterine inversion: two cases. J GynecolObstetBiolReprod (Paris) 2002;31:668-71.

13. Hostetler DR, Bosworth MF. Uterine inversion: a life threatening obstetric emeregency. Journal of the American board of family practice 2000;13:120-123.

14. Johnson A. A new concept in the replacement of the inverted uterus and a report of nine cases. Am J ObstetGynaecol 1949;57:557-562.

15. Rocconi RH, Warner K, Chiang S. Postmenopausal uterine inversion associated with endometrial polyps. Obstetrics \& gynaecology 2003;102:521-3.

16. C Georgiou. Balloon tamponade in the management of postpartum haemorrhage: a review. BJOG 2009;116:748757.

17. Lalonde A, Daviss BA, Acosta A, Herschderfer K. Postpartum hemorrhage today: ICM/FIGO initiative 20042006. Int J Gynecol Obstet 2006;94(3):243-53. 